\title{
Problemáticas socioambientais decorrentes da Canalização do Rio Granjeiro em Crato-CE
}

\author{
Environmental Problems Due to the Plumbing of the River Granjeiro in Crato-CE
}

\author{
CASTRO $^{1}$, F. F. B.; MENEZES ${ }^{2}$, K. W. S.;
}

fernandacastrol@hotmail.com

\begin{abstract}
Resumo
Este trabalho é fruto de uma pesquisa realizada durante o curso de especialização em Educação Ambiental e Desenvolvimento Sustentável, na Faculdade Juazeiro do Norte - FJN, onde pretendemos discorrer sobre os principais impactos socioambientais, causados a partir da canalização do Rio Granjeiro, em decorrência da extensão do processo de urbanização na cidade do Crato-Ce. Sendo assim, objetivamos analisar como a intervenção humana de maneira irregular e a falta de planejamento e gestão contribuíram para as cheias que ocorreram em 2011, 2012 e a mais recente em abril de 2015, e quais as medidas governamentais realizadas, no intuito de ajudar a população residente do entorno, a fim de promover um debate que venha contribuir com a minimização desses impactos. Acreditamos que a solução para os problemas decorrentes da canalização do Rio Granjeiro partem primeiramente do conhecimento acerca da problemática ambiental envolvida, da conscientização por parte da população, bem como, da iniciativa do poder público, considerando as condições naturais a fim de estabelecer uma interação equilibrada entre sociedade e natureza.
\end{abstract}

Palavras-chave: Canalização; Rio Granjeiro; impactos socioambientais.

\begin{abstract}
This work is the seed of a research that happened during the specialization course in Environmental Education and Sustainable Development, at the University of Juazeiro do Norte - UJN, where we aim to discuss about the main environmental impacts caused by the plumbing of the River Granjeiro, a result of the extension of the urbanization process in the city of Crato-Ce. With that being said, our main goal is to analyze how the irregular human intervention and the lack of planning and management contributed for the floods that happened in the years of 2011, 2012 and more recently in April of 2015, furthermore, what are the measures taken by the government with the intention of helping the citizens of the city that aims to promote a debate that can contribute to the minimization of such impacts. We believe that the resolution for such problems brought by the plumbing of the River Granjeiro comes primarily from the knowledge about the environmental problematic involved, from the awareness of the population, also the initiative of the public power, considering the natural conditions with the aim of establishing a balanced interaction between society and nature.
\end{abstract}

Keywords: Plumbing; River Granjeiro; environmental impacts.

\section{INTRODUÇÃO}

Grande parte dos municípios brasileiros surgiram nas margens de rios visando possibilidades de sobrevivência. Crato não foge a essa realidade, localizado no Cariri Cearense, extremo-sul do Estado do Ceará, integrante da Região Metropolitana do Cariri, este município que faz divisa com o Pernambuco é conhecido por muitos como o "Oásis do Sertão", devido as suas riquezas naturais. Sua posição no sopé da chapada do Araripe, bem como sua estrutura permeável de rochas sedimentares, possui aproximadamente 52 fontes perenes.

Climatologicamente o município embora possua características do semiárido nordestino, por está localizado a barlavento da Chapada do Araripe, conta com temperaturas amenas, devido a sua 
função de receptora de umidade por sua altitude. Sua pluviosidade é de 1090,9 mm anuais, com chuvas concentradas de janeiro a abril e temperaturas que oscilam entre $23^{\circ} \mathrm{C}$ e $26^{\circ} \mathrm{C}$, com média anual de $25^{\circ} \mathrm{C}$, podendo chegar a mínimas absolutas de até $15^{\circ} \mathrm{C}$ nas áreas mais elevadas. (FUNCEME, 1990).

A cidade viu o aumento da sua população ao redor do Rio Granjeiro, de modo que para efetivar esse crescimento urbano, tomou-se como medida a sua canalização. Em decorrência deste fato, tornou-se frequente o número de enchentes e inundações que periodicamente afetam a vida da população de Crato a cada período chuvoso.

As alterações no meio ambiente decorrentes das atividades humanas vêm provocando desequilíbrios no meio natural e causando inúmeros danos socioambientais, assim sendo, este trabalho objetiva apresentar as consequências da canalização do Rio Granjeiro, pontuando os principais impactos socioambientais, a partir da intervenção humana.

Destacamos a necessidade de analisar a problemática socioambiental a partir da relação estabelecida entre sociedade e natureza, visto que estes são elementos que encontram-se intrinsecamente ligados e dentro da sua complexidade compõe uma totalidade.

\section{METODOLOGIA}

A construção da metodologia baseia-se em duas etapas. Primeiramente foi realizado levantamento bibliográfico e documental referente à área de estudo e a temática ambiental. Nesta fase, foram analisados livros, dissertações, teses e artigos científicos, bem como plano diretor do município e a base eletrônica órgãos públicos e privados. Posteriormente foram realizados trabalhos de campo no recorte espacial delimitado, seguidos pela interpretação e sistematização dos dados coletados.

Ressaltamos os trabalhos de campo, uma vez que, sua importância é fundamentada na possibilidade de descobrir novos elementos da realidade, no intuito de promover uma releitura do espaço. Nesse sentido, foram feitas visitas de campo durante as cheias de 2011, 2012 e a mais recente, em abril de 2015, sendo que esta ocorreu com menor intensidade. Além disso, buscamos analisar os impactos sociais trazidos pelas enchentes a população, através de conversas informais com os moradores residentes do entorno do canal.

\section{RESULTADOS E DISCUSSÃO}

Os desastres naturais tanto aqueles de grande intensidade quanto os de menor impacto, acabam sempre ocasionando danos e perdas, seja de caráter social, econômico, ambiental e até mesmo cultural. Embora sejam causados por fenômenos e desequilíbrios da natureza, faz-se 
necessário o debate acerca da ação humana e sua participação na intensificação de alguns deles. Para isso, é preciso analisar como e porque estes vêm se manifestando no território.

Os desastres naturais podem ser provocados por diversos fenômenos, tais como: inundações, escorregamentos, erosão, terremotos, tornados, furacões, tempestades, estiagem, entre outros. Além da intensidade dos fenômenos naturais, o acelerado processo de urbanização verificado nas últimas décadas, em várias partes do mundo, inclusive no Brasil, levou ao crescimento das cidades, muitas vezes em áreas impróprias à ocupação, aumentando as situações de perigo e de risco a desastres naturais. (TOMINAGA, 2009 p. 12).

As Inundações representam o transbordamento das águas de um curso d'agua, atingindo a planície de inundação ou área de várzea enquanto as enchentes ou cheias são definidas pela elevação do nível d'agua no canal de drenagem, devido o aumento da vazão, atingindo a cota máxima do canal, porém, sem extravasar (AMARAL \& RIBEIRO, 2009). Como podemos observar na figura abaixo:

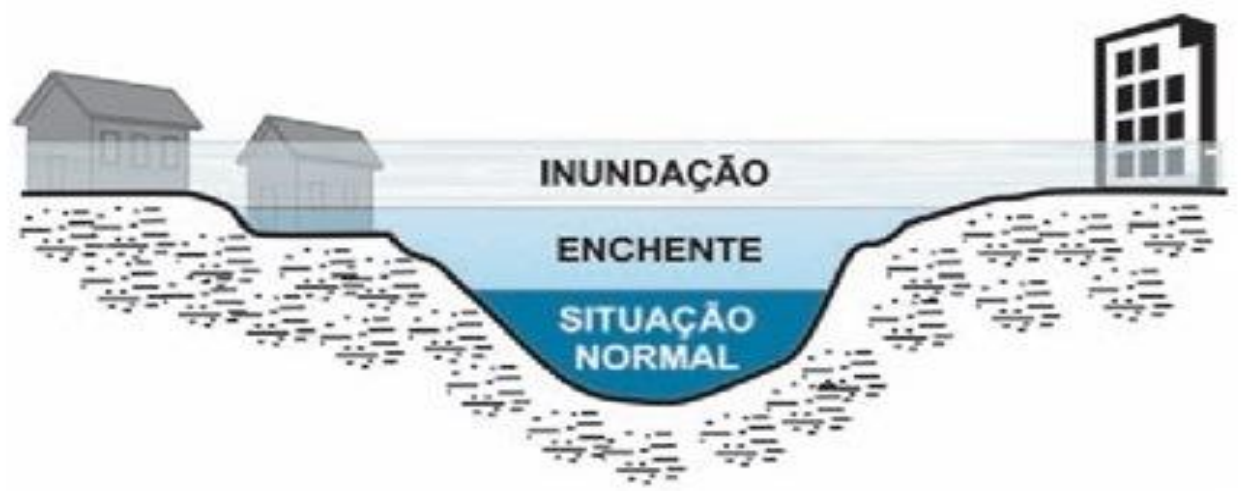

Figura 1. Perfil esquemático do processo de enchente e inundação. Fonte: Tominaga et al (2009).

A cidade em estudo cresceu sob as margens do Rio Granjeiro, que teve sua mata ciliar destruída no médio e baixo curso, com isso, foi construído um canal, por onde suas águas devem atravessar a cidade. Com a impermeabilização do solo e a construção de um estreito canal de concreto, com elevado risco de extravasamento, há um aumento do escoamento superficial, tornando trágica a quadra chuvosa da região. Nesse sentido Tucci afirma que:

[...] As enchentes aumentam a sua frequência e magnitude devido à ocupação do solo com superfícies impermeáveis e rede de condutos de escoamentos. O desenvolvimento urbano pode também produzir obstruções ao escoamento como aterros e pontes, drenagens inadequadas e obstruções ao escoamento junto a condutos e assoreamento [...] (TUCCI 1999, p. 02):

Segundo Guerra (1998) a cobertura vegetal em uma floresta pode atuar reduzindo o volume de água que chega ao solo e alterando a distribuição das gotas afetando assim a energia cinética. Deste modo, a vegetação da encosta possui o papel de amenizar os impactos das gotas de chuva e a velocidade do fluxo de água, de modo que minimiza a velocidade da água. Nesse sentido, o desmatamento da mata ciliar juntamente a canalização retificada do Rio Granjeiro, alteram a sua 
forma natural, ocasionando à perda dos meandros, fenômeno que acelera o escoamento das águas pluviais, sobretudo em períodos de intensa precipitação.

Para Jacobi (2006. p. 01):

A dimensão dos problemas ambientais tem se avolumado de forma crescente no contexto urbano metropolitano brasileiro. Sua lenta resolução tem provocado um descontrole em alguns setores estratégicos para a garantia da qualidade de vida, aumento desmesurado de enchentes, dificuldades na gestão dos resíduos sólidos e interferência crescente do despejo inadequado de resíduos sólidos, impactos cada vez maiores da poluição do ar na saúde da população e contínua degradação dos recursos hídricos.

As chuvas do primeiro semestre de 2011 atingiram 120,2 mm no dia 3 de janeiro e $162 \mathrm{~mm}$ no dia 28 do mesmo mês (FUNCEME, 2012). Tais índices pluviométricos foram suficientes para ocasionar a quebra do canal e provocar enchentes em grande parte do centro da cidade. A força das águas através do transbordamento do canal arrastou vários carros, invadiu comércios no centro da cidade, danificou postos de gasolina, de modo que algumas famílias ficaram desabrigadas (Figura 02).

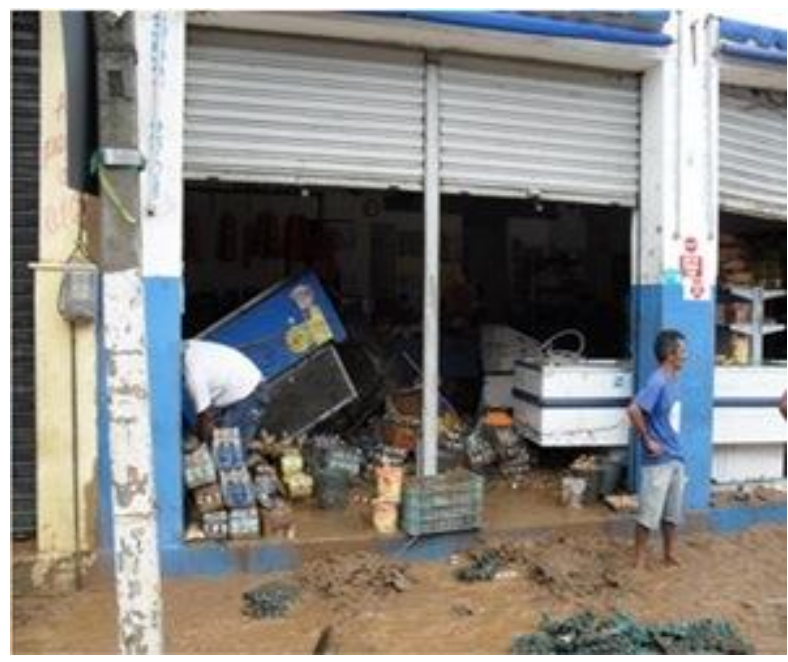

Figura 2. Rua Bárbara de Alencar, enchente em 28.01.2011. Fonte: Castro (2011)

Além disso, o lixo que é jogado nas ruas e mesmo do canal do Rio Granjeiro vem agravando cada vez mais a situação das enchentes bem como, aumenta a incidência de doenças a população (Figura 03). 


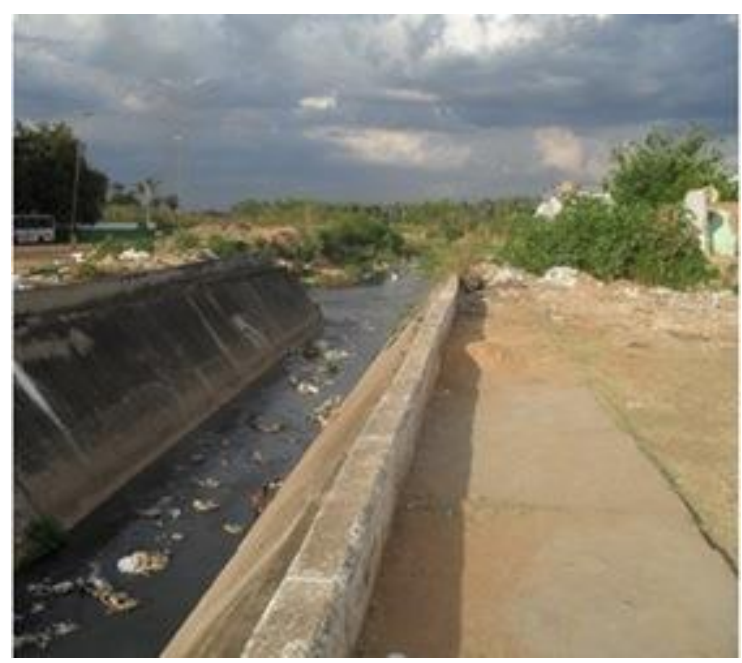

Figura 3. Disposição irregular do lixo no canal do Rio Granjeiro em 02.02.2012. Fonte: Castro (2012)

Após a cheia em 2011, foram feitas obras de reparo no intuito de "resolver" o problema. A prefeitura municipal declarou estado de calamidade pública, para obtenção de recursos do governo estadual. Na época a mídia local falava em um total de 4 milhões de reais a serem aplicados na obras emergenciais. Destes, a prefeitura teria utilizado 2 milhões que em pouco mais de um ano foram destruídas pela ocasião de novas chuvas que atingiram a cidade. A falta de caráter qualitativo na realização das obras de reparo em 2011 mostra que o dinheiro público vem sendo gasto com obras mal planejadas, que não são pensadas para promover a segurança e o bem-estar social, já que são apenas "remendos" do que já foi feito de maneira errada.

Em 05 de março de 2012, a cidade enfrentou um total mensal de 298,4 mm de chuva (FUNCEME, 2012), ocasionando outras inundações na cidade, e destruindo as obras de reparo que tinham sido iniciadas um ano antes, porém não haviam sido concluídas (Figura 04).

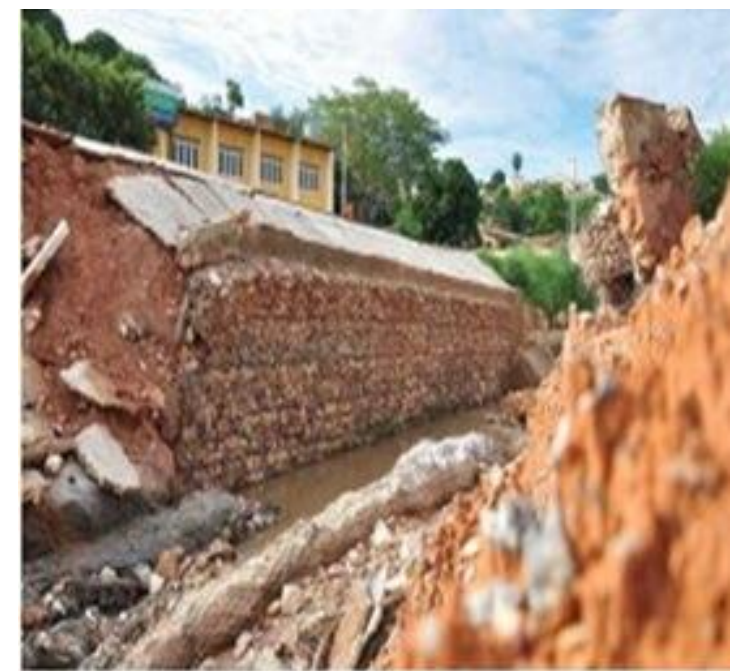

Figura 4. Obra de reparo emergencial desfeita em fevereiro de 2012. Fonte: Google imagens 
A população cratense viu parte dos impactos causados na chuva do dia 28 de janeiro de 2011 se repetirem no ano de 2012 e a convivência com o medo e a insegurança por parte dos que residem ás margens do canal é frequente a cada período chuvoso. Em 22 de abril de 2015 a FUNCEME registrou uma chuva de $162 \mathrm{~mm}$ no município, despertando mais uma vez o pânico entre os moradores, felizmente a chuva durou apenas alguns minutos, o que evitou uma nova catástrofe no município.

Os residentes ao longo da Avenida José Alves de Figueiredo, as margens do canal especialmente, próximo à prefeitura municipal encontram-se expostas à água poluída, lançamento de esgotos doméstico, causando mau cheiro devido a grande quantidade de lixo, fatores contribuintes para a poluição e contaminação destas áreas. No entanto, é necessário destacar que muitos dos moradores que ali se encontram não o fizeram por opção, contudo as condições impostas pelo atual sistema a qual estamos inseridos em muitos casos os obrigam a tal propensão.

Um dos principais desafios da contemporaneidade é sem dúvidas que o homem crie espaços sustentáveis com condições que assegurem uma melhor qualidade de vida. Como observa Botelho (1999), é preciso orientar a ocupação humana a fim de que sejam resguardadas as áreas destinadas à preservação ambiental, tendo em vista a conservação dos recursos naturais, a forte instabilidade ou fragilidade ambientais e a alta susceptibilidade à erosão e movimentos de massa que certas porções da paisagem podem apresentar.

\section{CONSIDERAÇÕES FINAIS}

A partir da análise de todos os fatores contribuintes para a existência da problemática vivenciada pela população cratense, com a crescente urbanização e consequentemente as enchentes providas da canalização do Rio Granjeiro, fica evidente que não apenas uma, mas várias são as ações que devem ser tomadas como solução para esse problema.

Consideramos que adotar práticas de reflorestamento na área montante do rio, isto é, na encosta, promovendo a redução da velocidade e volume de água que chegaria ao canal, seria uma das maneiras de amenizar o problema. Do mesmo modo, é necessario evitar a disposição inadequada de resíduos sólidos no canal que favorecem o assoreamento, enchentes, e a contaminação dos corpos hídricos, uma vez que, essas ações muitas vezes ocasionadas pela falta de conscientização da população ou mesmo de informação agrava o problema substancialmente.

Percebe-se a partir dos levantamentos feitos nesta pesquisa referentes aos anos de 2011, 2012 e 2015 que esses eventos não irão deixar de acontecer, o que reforça a importância de novas medidas de prevenção, que envolvam os órgãos públicos e a população, bem como a importância de 
novos estudos desta natureza, no intuito de promover informações sobre a dinâmica desta problemática, visando contribuir com a melhor qualidade de vida daqueles que ali residem.

\section{REFERÊNCIAS}

AMARAL, R. RIBEIRO, R. R. Inundação e Enchentes. In: TOMINAGA, L. K; SANTORO, J; AMARAL, R. do (Org). Desastres naturais: conhecer para prevenir. $1^{\text {a }}$ Ed. São Paulo: Instituto Geológico, 2009. p. 41-52.

BOTELHO, R. G. M. Planejamento ambiental em microbacia hidrográfica. In GUERRA, A.J. T.; SILVA, A. S. da E BOTELHO, R. G. M. (org.) Erosão e conservação dos solos: conceitos, temas e aplicações. Rio de Janeiro: Bertrand Brasil, 1999. p. 269-300.

FUNCEME. Balanço hídrico do Ceará. Fortaleza: 1990. Disponível em: http://www.funceme.br/. Acesso em 09/07/2015.

GUERRA, A. J. T. \& CUNHA, S. B. Geomorfologia: uma atualização de bases e conceitos. $3^{\text {a }}$ Ed. Rio de Janeiro: Bertrand Brasil,1998. 472 p.

JACOBI, P. Dilemas socioambientais na gestão metropolitana: do risco à busca da sustentabilidade urbana. Revista de Ciências Sociais Política e Trabalho. nº 25. João Pessoa, 2006. p. 115-134.

TOMINAGA, L. K. Desastres Naturais: Por que ocorrem? In: TOMINAGA, L. K; SANTORO, J; AMARAL, R. do (Org). Desastres naturais: conhecer para prevenir. $1^{\text {a }}$ Ed. São Paulo: Instituto Geológico, 2009. p 13-23.

TUCCI. C. E. M. Controle de Enchentes. In: Hidrologia Ciência e Aplicaçãa. $3^{\circ}$ Ed. Porto Alegre: ABRH- Editora UFRGS, 2002, p. 621-658.

TUCCI, C. E. M. Carlos, Aspectos institucionais no controle de inundações. In: I Seminário de recursos hídricos do centro-oeste de Brasília. Disponível em: <http://www.rhama.net/download/artigos/artigo9.pdf. Acesso em 03/03/2015.

Recebido em: 14/08/2016

Aceito para publicação em: 01/10/2016 